Check for updates

Cite this: Chem. Sci., 2017, 8, 7047

\title{
Copper-catalyzed cyanothiolation to incorporate a sulfur-substituted quaternary carbon center
}

\author{
Yubing Huang, Xianwei Li, Xu Wang, Yue Yu, Jia Zheng, Wanqing Wu* \\ and Huanfeng Jiang $\mathbb{D}$ *
}

Sulfur-containing nitriles have important research value in the life sciences due to their diverse biological activities resulting from the sulfur and cyano functional groups. Herein, a copper-catalyzed cyanothiolation of $\mathrm{N}$-tosylhydrazones with thiocyanates to generate $\alpha$-arylthioalkanenitriles bearing sulfur-substituted quaternary carbon center atoms has been described. This novel protocol involves the procedure of copper carbene species promoting $\mathrm{S}-\mathrm{CN}$ bond cleavage and $\mathrm{C}-\mathrm{CN} / \mathrm{C}-\mathrm{S}$ bond reconstruction to introduce both sulfur and cyano groups onto a single carbon center. This cyanothiolation reaction will greatly enhance the synthetic utility of carbenoid species as new entries for the construction of diverse heteroatom-containing nitriles via cyanofunctionalization of metal-carbene species.

Received 29th June 2017

Accepted 15th August 2017

DOI: $10.1039 / \mathrm{c} 7 \mathrm{sc} 02867 \mathrm{a}$

rsc.li/chemical-science

difunctionalization of metal-carbene species has been of concern, as it provides direct pathways to enhance the synthetic

\section{Introduction}

Transition metal-catalyzed cyanofunctionalization reactions are direct and powerful strategies for the introduction of cyano groups and another functional groups simultaneously into one single molecular framework. It is known that cyano groups are often building blocks of pharmaceuticals, ${ }^{1}$ agrochemicals and functionalized materials, and are easily transformed into aldehydes, amines, amides or other carboxyl derivatives. Conceivably, the development of cyanofunctionalization is extremely desirable in the construction of functionalized nitriles, ${ }^{2}$ and it has caught increasing attention in the past decades. Previous cyanofunctionalizations generally required the cleavage of the $\mathrm{RX}-\mathrm{CN}\left(\mathrm{X}=\mathrm{Si},{ }^{3} \mathrm{Ge},{ }^{4} \mathrm{~B},{ }^{5} \mathrm{Sn},{ }^{6} \mathrm{~S},{ }^{7} \mathrm{O},{ }^{8} \mathrm{C},{ }^{9}\right.$ or $\left.\mathrm{N}^{10}\right)$ bond through oxidative addition of transition metal $(\mathrm{M}=\mathrm{Ni}, \mathrm{Pd}, \mathrm{Pt})$ complexes, and immediately, both functional fragments were simultaneously installed at disparate carbon atoms of versatile substrates, including arynes, alkenes and alkynes (Scheme 1a). However, a process to incorporate two cleaved functional fragments onto a single carbon atom via transition metal-catalyzed cyanofunctionalization has never been realized, and is still a challenging issue.

Carbenoid species, ${ }^{11}$ generated easily from diazo compounds, are a class of significant reactive intermediates, as they display both electrophilic and nucleophilic reactivity in a single carbon center. $^{11 g}$ In recent years, gem-

Key Laboratory of Functional Molecular Engineering of Guangdong Province, School of Chemistry and Chemical Engineering, South China University of Technology, Guangzhou 510640, China. E-mail: cewuwq@scut.edu.cn; jianghf@scut.edu.cn $\dagger$ Electronic supplementary information (ESI) available. CCDC 1546232. ESI and crystallographic data in CIF or other electronic format. See DOI: $10.1039 / \mathrm{c} 7 \mathrm{sc} 02867 \mathrm{a}$ applications of carbenoid species. In this respect, the chemical bond cleavage of heteroatom-containing reactants and installation of both cleaved carbon and heteroatom fragments onto carbenoid species via transition metal catalysis is one of the most attractive and promising methods to incorporate a heteroatom-containing quaternary carbon center. Currently, examples of inserting nitrogen ${ }^{12}$ and oxygen ${ }^{13}$ which have small atomic radii, are limited. In addition, introducing the large steric hindrance of a sulfur atom into the metal-carbene through cleavage of the $\mathrm{S}-\mathrm{C}$ bond to construct a sulfursubstituted quaternary carbon is generally done via the rearrangement of sulfonium ylide, ${ }^{14}$ where the employment of a noble metal catalyst is demanded. Sulfur-containing compounds, involving diaryl sulfides and their higher

(a) Previous cyanofunctionalizations

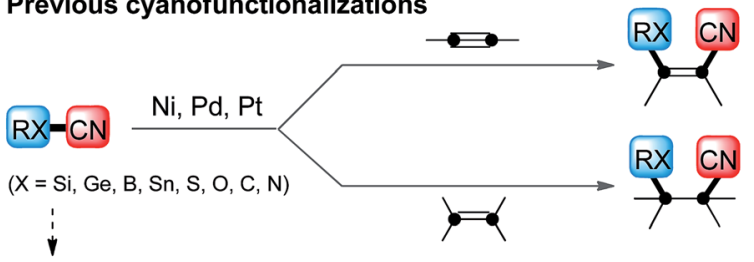

(b) This work $(X=S)$

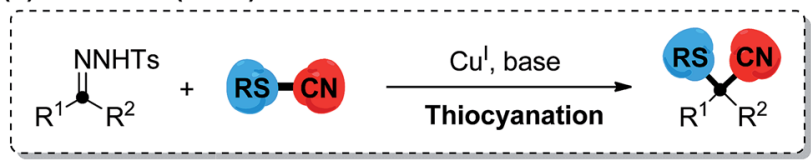

Scheme 1 Transition metal-catalyzed cyanofunctionalization reactions. 
oxidation homologues, display a variety of biological and pharmaceutical activities, ${ }^{15}$ such as antifungal, antibacterial, and antitumoral activities. To our knowledge, direct cyanothiolation of metal-carbene species to construct sulfurcontaining nitriles remains unexplored. Based on our previous studies ${ }^{\mathbf{1 6}}$ on copper-catalyzed coupling reactions for the formation of carbon-heteroatom bonds, herein, we propose a copper-catalyzed cyanothiolation of $N$-tosylhydrazones with thiocyanates to incorporate a sulfur-substituted quaternary carbon center through a copper carbene species promoting $\mathrm{S}-$ $\mathrm{CN}$ bond cleavage and a $\mathrm{C}-\mathrm{CN} / \mathrm{C}-\mathrm{S}$ bond reconstruction process (Scheme 1b). This protocol to install both the sulfur and cyano group simultaneously in a one-step manner to access diverse $\alpha$ arylthioalkanenitriles would find its potential applications in the fields of pharmaceutical and materials science.

\section{Results and discussion}

We initiated our studies with the reaction between the $\mathrm{N}$ tosylhydrazone of acetophenone (1a) and 1.0 equiv. of 1-methyl4-thiocyanatobenzene (2a) with 5 mol\% CuTC and 2 equiv. of DBU in $0.5 \mathrm{~mL}$ of MeCN. Gratifyingly, the desired product 3aa was given in $70 \%$ yield after $12 \mathrm{~h}$ at $90{ }^{\circ} \mathrm{C}$ under a nitrogen atmosphere. Various types and loadings of copper catalysts were then screened (Table 1, entries 1-6), and the yield of 3aa increased to $76 \%$ when $10 \mathrm{~mol} \% \mathrm{CuSCN}$ was used as a catalyst (entry 6). An investigation into the effects of the $2 \mathrm{a}$ and DBU loadings (entries 6-9) revealed that when employing 1.5 equiv. of $2 \mathrm{a}$ and 1 equiv. of DBU, the yield could reach $94 \%$ (entry 8 ). It was found that different solvents did not have much effect on the yield (entries 10-11). Additionally, control experiments showed that no reaction occurred in the absence of the $\mathrm{Cu}$ catalyst or base.

Table 1 Optimization of the reaction conditions ${ }^{a}$

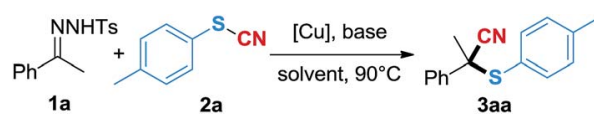

\begin{tabular}{llllll}
\hline & & $2 a$ & & & \\
Entry $^{a}$ & {$[\mathrm{Cu}](\mathrm{mol} \%)$} & (equiv.) & Base (equiv.) & Solvent & Yield $^{b}(\%)$ \\
\hline 1 & CuTC (5) & 1.0 & DBU (2) & MeCN & 70 \\
2 & CuSCN (5) & 1.0 & DBU (2) & MeCN & 58 \\
3 & Cu(MeCN) ${ }_{4}$ FF $_{6}(5)$ & 1.0 & DBU (2) & MeCN & 21 \\
4 & CuI (5) & 1.0 & DBU (2) & MeCN & 36 \\
5 & CuTC (10) & 1.0 & DBU (2) & MeCN & 55 \\
6 & CuSCN (10) & 1.0 & DBU (2) & MeCN & 76 \\
7 & CuSCN (10) & 1.0 & DBU (1) & MeCN & 83 \\
8 & CuSCN (10) & 1.5 & DBU (1) & MeCN & $\mathbf{9 4}(\mathbf{9 1})^{c}$ \\
9 & CuSCN (10) & 2.0 & DBU (1) & MeCN & 81 \\
10 & CuSCN (10) & 1.5 & DBU (1) & DCE & n.d. \\
11 & CuSCN (10) & 1.5 & DBU (1) & DMF & 52
\end{tabular}

${ }^{a}$ Reaction conditions: all reactions were performed with $1 \mathrm{a}(0.1 \mathrm{mmol})$, 2a, catalyst and DBU in $0.5 \mathrm{~mL}$ of solvent at $90{ }^{\circ} \mathrm{C}$ under a nitrogen atmosphere for $12 \mathrm{~h} .{ }^{b}$ GC-MS yield using $n$-dodecane as an internal standard. n.d. $=$ not detected. ${ }^{c}$ Isolated yield.
With the optimal reaction conditions in hand, we subsequently examined a series of $N$-tosylhydrazones for this transformation (Table 2). Both the electron-rich groups ( $\mathrm{Me}, \mathrm{MeO}$ and $\mathrm{Ph}$ ) and the electron-poor groups (F, $\mathrm{CF}_{3}, \mathrm{Br}, \mathrm{CO}_{2} \mathrm{Me}, \mathrm{CN}$ and $\mathrm{SO}_{2} \mathrm{Me}$ ) at the para-position of the phenyl ring were tolerated in this conversion, and the corresponding products (3ba$3 \mathbf{j a})$ were given in good to excellent yields. When the metasubstituted group was methyl (3ka) or chloride (3la), the reaction gave the desired products in $90 \%$ and $87 \%$ yields, respectively. The difluoro-substituted substrates could transfer to the corresponding product $3 \mathrm{ma}$ in $78 \%$ isolated yield. It should be noted that naphthalene and the heterocyclic (furan and thiophene) substrates underwent the transformations smoothly, affording the desired products 3na-3pa in 95\%, 77\% and $81 \%$ yields, respectively. Moreover, replacing the $\mathrm{R}^{1}$ group with a sterically hindered isopropyl (1q) or cyclopropyl (1r) had no obvious impact on the yields, and the corresponding products could be generated in good yields (3qa-3ra). It should be noted that when using the $N$-tosylhydrazones bearing tetrahydronaphthalene (1s) and chroman (1t) as the substrates, the cyanothiolation reaction gave the corresponding products $3 \mathbf{s a}$ and 3ta in $87 \%$ and $92 \%$ yields. The structure of 3na was further confirmed by X-ray crystallographic analysis.

Next, the substrate scope of the thiocyanates was examined and the results are shown in Table 3. Electron-withdrawing and electron-donating groups were well tolerated on the aryl rings of the thiocyanates (3ac-3ag). Among them, substrates with halogen groups, 3ac and 3ag, delivered the expected products in relatively lower yields of $88 \%$ and $82 \%$, respectively. When 2 thiocyanatonaphthalene was used as a substrate, the

Table 2 Substrate scope of $N$-tosylhydrazones ${ }^{a}$

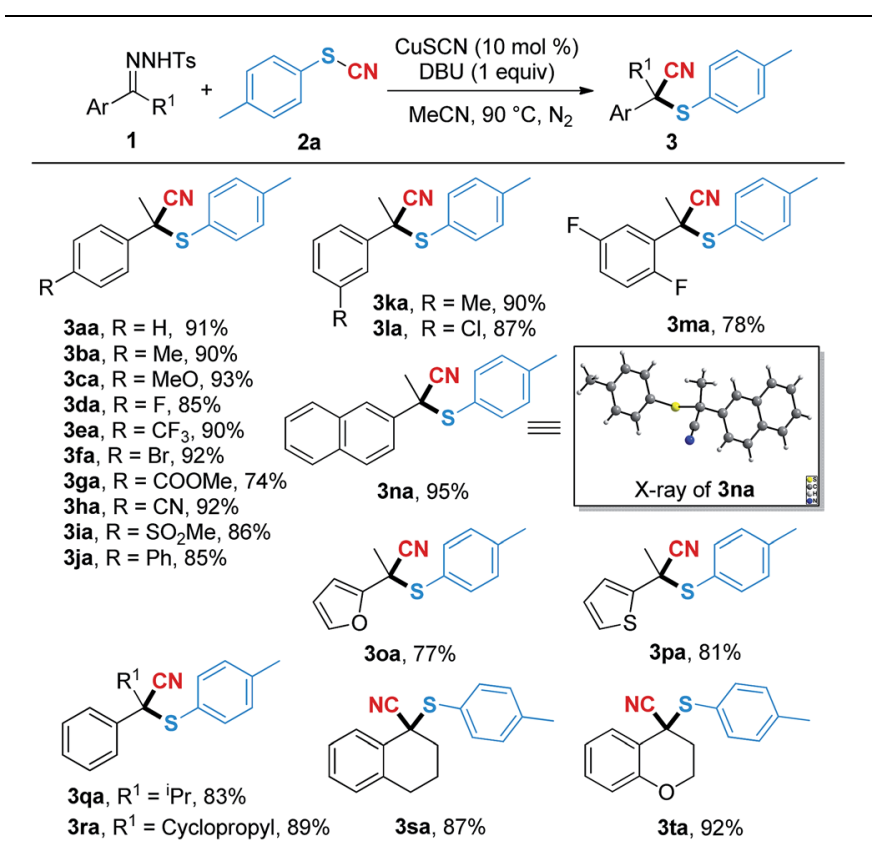

${ }^{a}$ Reaction conditions: $\mathbf{1}(0.2 \mathrm{mmol}), \mathbf{2 a}(0.3 \mathrm{mmol})$, CuSCN $(0.02 \mathrm{mmol})$ and $\mathrm{DBU}(0.2 \mathrm{mmol})$ in $1.0 \mathrm{~mL}$ of $\mathrm{MeCN}$ at $90^{\circ} \mathrm{C}$ for $12 \mathrm{~h}$. Isolated yield. 
Table 3 Substrate scope of thiocyanates ${ }^{a}$

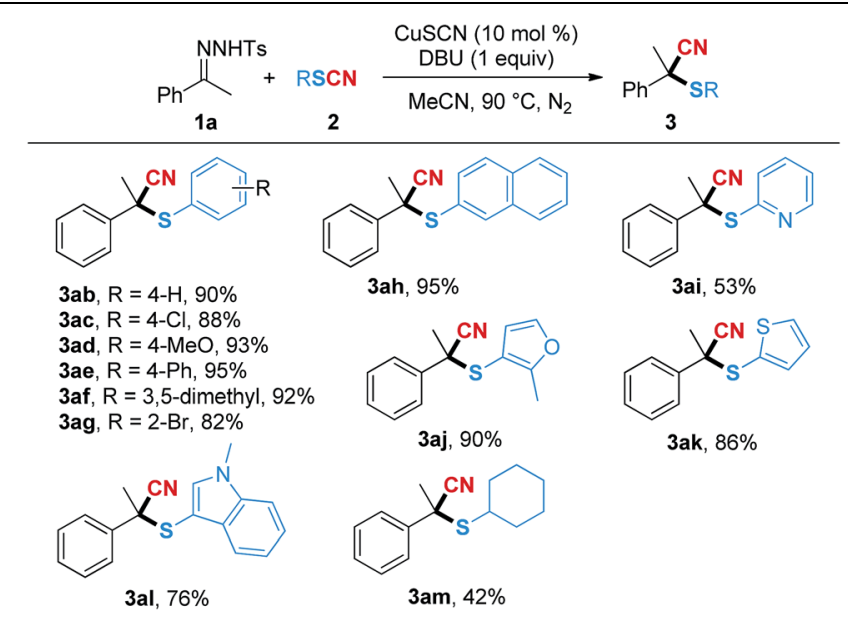

${ }^{a}$ Reaction conditions: 1a $(0.2 \mathrm{mmol}), 2(0.3 \mathrm{mmol})$, CuSCN $(0.02 \mathrm{mmol})$, and $\mathrm{DBU}(0.2 \mathrm{mmol})$ in a $1.0 \mathrm{~mL} \mathrm{MeCN}$ at $90^{\circ} \mathrm{C}$ for $12 \mathrm{~h}$. Isolated yield.

corresponding product 3ah was isolated in 95\% yield. However, the yield of 3ai, bearing a pyridine ring, was decreased to $53 \%$, while the thiocyanates containing other heterocycles such as furan, thiophene and 1-methylindole were suitable substrates and converted to the desired products in good yields (3aj-3al). Moreover, when thiocyanatocyclohexane was used in the reaction, a $42 \%$ isolated yield of product 3am could be obtained.

Interestingly, when the ortho-substituted (o-methyl and $o$ chloro) $N$-tosylhydrazones were used as the substrates, the reaction gave the nitrile products (3ua and 3va) in 91\% and 95\% isolated yields instead of the cyanothiolation products (Table 4, eqn (1)). We suspected that the reaction might first undergo the cyano group insertion process after the cleavage of the S-CN bond, and subsequently, the release of the sulfur group was promoted due to the space hindrance of the ortho-substituents. Moreover, when the ortho-fluoro-substituted $\mathrm{N}$-tosylhydrazone

Table 4 Formation of nitrile products ${ }^{a, b}$

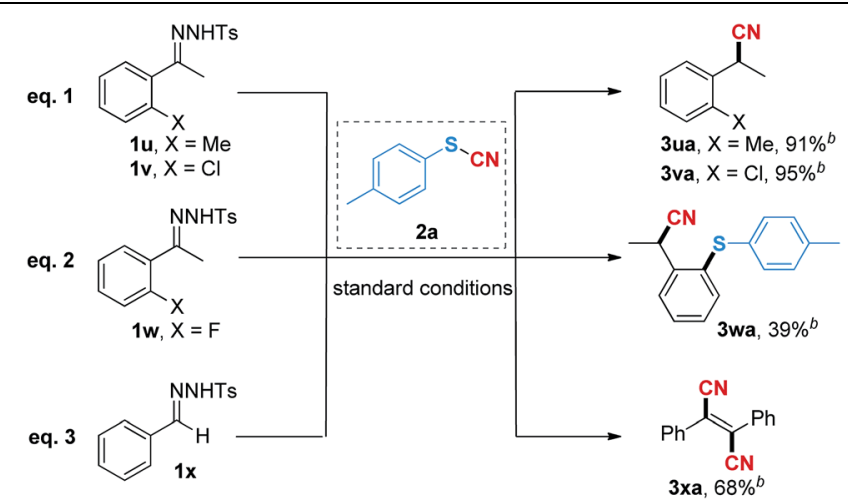

${ }^{a}$ Reaction conditions: $\mathbf{1}(0.2 \mathrm{mmol}), \mathbf{2 a}(0.3 \mathrm{mmol})$, CuSCN $(0.02 \mathrm{mmol})$, and DBU $(0.2 \mathrm{mmol})$ in $1.0 \mathrm{~mL}$ of MeCN at $90{ }^{\circ} \mathrm{C}$ for $12 \mathrm{~h} .{ }^{b}$ Isolated yield. was employed, the ortho-thiophenyl-substituted nitrile product 3wa was afforded in 39\% yield (Table 4, eqn (2)), suggesting that the cleaved sulfur group was further involved in the coupling reaction $^{\mathbf{1 7}}$ under copper catalysis. In order to validate our hypothesis, we used the $N$-tosylhydrazone of benzaldehyde as a substrate to react with thiocyanatobenzene $\mathbf{2 a}$ under the standard reaction conditions. As expected, the unstable intermediate produced by the insertion of the cyano group underwent the subsequent coupling process to give fumaronitrile $3 \mathbf{x a}$ in $68 \%$ yield (Table 4 , eqn (3)), which could not be obtained directly through the dimerization of phenylacetonitrile in the current system (see the $\mathrm{ESI} \dagger$ for details).

In order to further study the reaction mechanism, several control experiments were performed (Scheme 2). Firstly, when using 1,2-di- $p$-tolyldisulfane and TMSCN as the substrates, 2a was generated in $78 \%$ yield (Scheme 2 , eqn (1)), which indicated that thiocyanate could be generated in a good yield under the standard conditions with TMSCN as the cyano source. To validate that the copper carbene species would promote the S-CN bond cleavage, we next mixed (1-diazoethyl) benzene ${ }^{18}$ and $2 \mathrm{a}$ in the reaction system without a base. However, 3aa was generated in only $21 \%$ yield (Scheme 2 , eqn (2a)), which might be due to the instability of the diazo compound at higher temperatures. In contrast, when DBU was added, the yield of 3aa was increased to $53 \%$ (Scheme 2, eqn (2b)), suggesting that DBU probably acted as both a ligand and a base to facilitate the reaction. However, when the reaction was conducted at room temperature with DBU added, 2a did not participate in the conversion (Scheme 2, eqn (2c)), therefore, a higher energy was required for the cleavage of the $\mathrm{S}-\mathrm{CN}$ bond in this cyanothiolation reaction.

Based on the above experimental results, a tentative mechanism is proposed for the copper-catalyzed cyanothiolation of $\mathrm{N}$-tosylhydrazone in Scheme 3. Initially, the diazo substrate $\mathbf{A}$ is released slowly from the $N$-tosylhydrazone in the presence of DBU, which would react with $\mathrm{Cu}^{\mathrm{I}}$ to give the copper carbene species B. We speculate that the generation of the product might be via two paths. In path a, the interaction of thiocyanate $\mathbf{2}$ and the copper carbene species $\mathbf{B}$ leads to the formation of the copper $^{\mathrm{III}}$ carbene species $\mathbf{C ,}^{\mathbf{1 2}}$ followed by migratory inser$\operatorname{tion}^{\mathbf{1 8 a , 1 9}}$ to give the intermediate $\mathbf{D}$. The reductive elimination

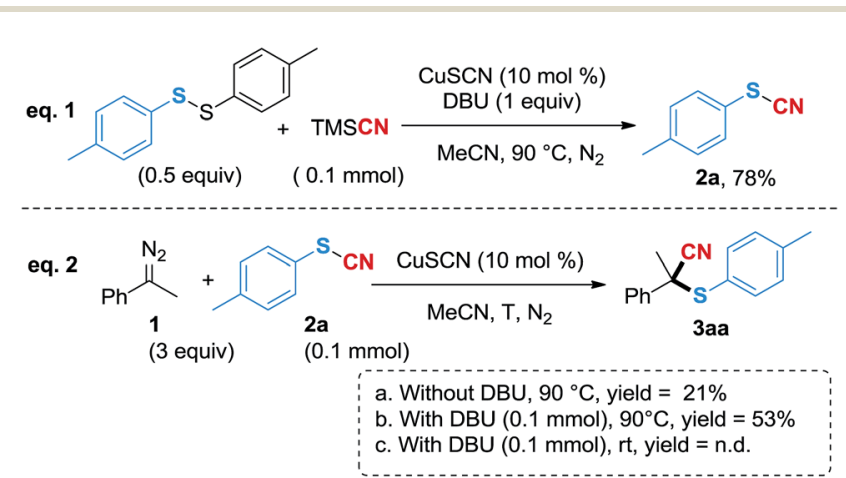

Scheme 2 Mechanistic studies. GC-MS yield using $n$-dodecane as an internal standard. n.d. $=$ not detected. 


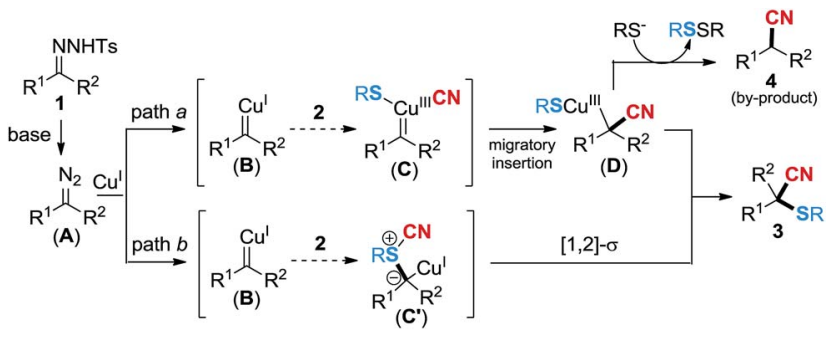

Scheme 3 Proposed mechanism.

of $\mathbf{D}$ provides the major product $\mathbf{3}$ and regenerates $\mathrm{Cu}^{\mathrm{I}}$. In addition, a small amount of intermediate $\mathbf{D}$ would take off the $\mathrm{RS}^{-}$group in the presence of the thiophenol anion, ${ }^{20}$ and disulfide ether would be generated as a by-product, followed by protonation ${ }^{19}$ to release the nitrile by-product 4 . In addition, the process of sulfur ylide rearrangement should be considered in the transformation as well. The copper carbene species $\mathbf{B}$ could react with thiocyanate 2 to generate sulfur ylide $\mathbf{C}^{\prime 14}$ via path $\mathrm{b}$, which may subsequently undergo [1,2]-sigmatropic rearrangement ${ }^{14 d}$ to access product 3 .

\section{Conclusions}

In summary, we have demonstrated a copper-catalyzed cyanothiolation reaction of $N$-tosylhydrazones with thiocyanates to give $\alpha$-arylthioalkanenitriles in high yields. Sulfur-containing nitriles have important research value in the life sciences due to their diverse biological activities resulting from the sulfur ${ }^{21}$ and cyano functional groups, which may dramatically modify the properties of each other, and even serve as intermediates in diverse transformations. This cyanothiolation reaction provides a valuable and efficient strategy to introduce both sulfur and cyano groups onto a single carbon center via a copper carbene species-promoting $\mathrm{S}-\mathrm{CN}$ bond cleavage and $\mathrm{C}-\mathrm{CN} / \mathrm{C}-\mathrm{S}$ bond reconstruction process. Furthermore, the inexpensive copper catalyst, readily available substrates and simple operation provide great advantages for the transformation. We speculated that the cyanothiolation reaction might occur through formation and conversion of the copper ${ }^{\mathrm{III}}$ carbene species or $[1,2]$ sigmatropic rearrangement of a sulfur ylide. Further investigations into chiral synthetic applications and elucidating the mechanism of this novel reaction are ongoing in our laboratory.

\section{Conflicts of interest}

There are no conflicts to declare.

\section{Acknowledgements}

This work was supported by the National Key Research and Development Program of China (2016YFA0602900), the National Natural Science Foundation of China (21420102003), and the Fundamental Research Funds for the Central Universities (2015ZY001).

\section{Notes and references}

1 (a) F. F. Fleming and Q. Wang, Chem. Rev., 2003, 103, 2035; (b) L. Wu and J. F. Hartwig, J. Am. Chem. Soc., 2005, 127, 15824; (c) G. Chen, Z. Wang, J. Wu and K. Ding, Org. Lett., 2008, 10, 4573; (d) F. F. Fleming, L. Yao, P. C. Ravikumar, L. Funk and B. C. Shook, J. Med. Chem., 2010, 53, 7902; (e) D. Li, P. Zhan, E. D. Clercq and X. Liu, J. Med. Chem., 2012, 55, 3595; $(f)$ D. Wang, F. Wang, P. Chen, Z. Lin and G. Liu, Angew. Chem., Int. Ed., 2017, 56, 2054.

2 (a) T. Wu, X. Mu and G. Liu, Angew. Chem., Int. Ed., 2011, 50, 12578; (b) W. Zhang, F. Wang, S. D. McCann, D. Wang, P. Chen, S. S. Stahl and G. Liu, Science, 2016, 353, 1014; (c) F. Wang, D. Wang, X. Wan, L. Wu, P. Chen and G. Liu, J. Am. Chem. Soc., 2016, 138, 15547.

3 S. Arai, T. Sato, Y. Koike, M. Hayashi and A. Nishida, Angew. Chem., Int. Ed., 2009, 48, 4528.

4 N. Chatani, N. Horiuchi and T. Hanafusa, J. Org. Chem., 1990, 55, 3393.

5 (a) M. Suginome, A. Yamamoto and M. Murakami, J. Am. Chem. Soc., 2003, 125, 6358; (b) M. Suginome, A. Yamamoto and M. Murakami, Angew. Chem., Int. Ed., 2005, 44, 2380.

6 Y. Obora, A. S. Baleta, M. Tokunaga and Y. Tsuji, J. Organomet. Chem., 2002, 660, 173.

7 M. Pawliczek, L. K. B. Garve and D. B. Werz, Org. Lett., 2015, 17, 1716.

8 D. C. Koester, M. Kobayashi, D. B. Werz and Y. Nakao, J. Am. Chem. Soc., 2012, 134, 6544.

9 (a) C. Nájera and J. M. Sansano, Angew. Chem., Int. Ed., 2009, 48, 2452; (b) S. M. Bonesi and M. Fagnoni, Chem.-Eur. J., 2010, 16, 13572; (c) Y. Minami, H. Yoshiyasu, Y. Nakao and T. Hiyama, Angew. Chem., Int. Ed., 2013, 52, 883.

10 B. Rao and X. Zeng, Org. Lett., 2014, 16, 314.

11 For recent reviews on metal carbenoids, see: (a) H. M. L. Davies and J. R. Manning, Nature, 2008, 451, 417; (b) M. P. Doyle, R. Duffy, M. Ratnikov and L. Zhou, Chem. Rev., 2010, 110, 704; (c) J. Barluenga and C. Valdés, Angew. Chem., Int. Ed., 2011, 50, 7486; (d) H. M. L. Davies, J. D. Bois and J.-Q. Yu, Chem. Soc. Rev., 2011, 40, 1857; (e) S.-F. Zhu and Q.-L. Zhou, Acc. Chem. Res., 2012, 45, 1365; (f) H. M. L. Davies and Y. Lian, Acc. Chem. Res., 2012, 45, 923; $(g)$ A. Ford, H. Miel, A. Ring, C. N. Slattery, A. R. Maguire and M. A. McKervey, Chem. Rev., 2015, 115, 9981; (h) M. Marinozzi, F. Pertusati and M. Serpi, Chem. Rev., 2016, 116, 13991.

12 G. Qin, L. Li, J. Li and H. Huang, J. Am. Chem. Soc., 2015, 137, 12490.

13 D. P. Hari and J. Waser, J. Am. Chem. Soc., 2016, 138, 2190. 14 (a) P. W. Davies, S. J.-C. Albrecht and G. Assanelli, Org. Biomol. Chem., 2009, 7, 1276; (b) M. D. Santos and P. W. Davies, Chem. Commun., 2014, 50, 6001; (c) T. H. West, S. S. M. Spoehrle, K. Kasten, J. E. Taylor and A. D. Smith, ACS Catal., 2015, 5, 7446; (d) Z. Song, Y. Wu, T. Xin, C. Jin, X. Wen, H. Sun and Q.-L. Xu, Chem. Commun., 2016, 52, 6079; (e) Z. Zhang, Z. Sheng, W. Yu, 
G. Wu, R. Zhang, W.-D. Chu, Y. Zhang and J. Wang, Nat. Chem., 2017, DOI: 10.1038/nchem.2789; (f) X. Xu, C. Li, M. Xiong, Z. Tao and Y. Pan, Chem. Commun., 2017, 53, 6219.

15 (a) I. C. Popoff, A. R. Engle, R. L. Whitaker and G. H. Singhal, J. Med. Chem., 1971, 14, 1166; (b) G. De Martino, M. C. Edler, G. La Regina, A. Coluccia, M. C. Barbera, D. Barrow, R. I. Nicholson, G. Chiosis, A. Brancale, E. Hamel, M. Artico and R. Silvestri, J. Med. Chem., 2006, 49, 947; (c) M. C. Bagley, T. Davis, M. C. Dix, V. Fusillo, M. Pigeaux, M. J. Rokicki and D. Kipling, J. Org. Chem., 2009, 74, 8336; (d) Z. Yuan, H.-Y. Wang, X. Mu, P. Chen, Y.-L. Guo and G. Liu, J. Am. Chem. Soc., 2015, 137, 2468.

16 (a) X. Tang, L. Huang, Y. Xu, J. Yang, W. Wu and H. Jiang, Angew. Chem., Int. Ed., 2014, 53, 4205; (b) Y. Gao, Y. Gao, X. Tang, J. Peng, M. Hu, W. Wu and H. Jiang, Org. Lett., 2016, 18, 1158; (c) Y. Huang, X. Li, Y. Yu, C. Zhu, W. Wu and H. Jiang, J. Org. Chem., 2016, 81, 5014.

17 E. Sperotto, G. P. M. van Klink, J. G. de Vries and G. van Koten, J. Org. Chem., 2008, 73, 5625.

18 (a) J.-S. Poh, D. N. Tran, C. Battilocchio, J. M. Hawkins and S. V. Ley, Angew. Chem., Int. Ed., 2015, 54, 7920; (b)
J.-S. Poh, S. Makai, T. von Keutz, D. N. Tran, C. Battilocchio, P. Pasau and S. V. Ley, Angew. Chem., Int. Ed., 2017, 56, 1864.

19 (a) M. Hu, C. Ni and J. Hu, J. Am. Chem. Soc., 2012, 134, 15257; (b) M. Hu, J. Rong, W. Miao, C. Ni, Y. Han and J. Hu, Org. Lett., 2014, 16, 2030; (c) Q. Lefebvre, E. Fava, P. Nikolaienko and M. Rueping, Chem. Commun., 2014, 50, 6617.

20 (a) Y. Yang, W. Dong, Y. Guo and R. M. Rioux, Green Chem., 2013, 15, 3170; (b) T. Castanheiro, M. Gulea, M. Donnard and J. Suffert, Eur. J. Org. Chem., 2014, 7814.

21 (a) Q.-Q. Yang, C. Xiao, L.-Q. Lu, J. An, F. Tan, B.-J. Li and W.-J. Xiao, Angew. Chem., Int. Ed., 2012, 51, 9137; (b) T.-R. Li, F. Tan, L.-Q. Lu, Y. Wei, Y.-N. Wang, Y.-Y. Liu, Q.-Q. Yang, J.-R. Chen, D.-Q. Shi and W.-J. Xiao, Nat. Commun., 2014, 5500; (c) Q. Wang, T.-R. Li, L.-Q. Lu, M.-M. Li, K. Zhang and W.-J. Xiao, J. Am. Chem. Soc., 2016, 138, 8360; (d) Q. Wang, X. Qi, L.-Q. Lu, T.-R. Li, Z.-G. Yuan, K. Zhang, B.-J. Li, Y. Lan and W.-J. Xiao, Angew. Chem., Int. Ed., 2016, 55, 2840. 